\title{
MộT SỐ YẾU TỐ LIÊN QUAN VỚI RỐI LOẠN GIÂC NGỦ TRÊN BÊNHH NHÂN ĐÁI THÁO ĐƯờnG CAO TUỔI TẠI BỆNH VIÊ̂N Y HỌC CỔ TRUYỀN HÀ ĐÔNG Nguyễn Trung Anh ${ }^{2}$, Nguyễ̂n Thị Thu Huơng ${ }^{1,2}$

\author{
${ }^{1}$ Bệnh viện Lão khoa Trung ương, ${ }^{2}$ Trường Đại học Y Hà Nội.
}

DOI: $10.47122 / v j d e .2020 .43 .3$

\section{ABSTRACT \\ Characteristics of sleep disturbance in elderly diabetic patients at Ha Dong Traditional Medicine Hospital}

Objectives: To assess several factors related to sleep disorder in elderly diabetic patients at Ha Dong Traditional Medicine Hospital. Methods: A cross-sectional study was performed in 107 patients aged 60 years or older, who was examined and treated at the $\mathrm{Ha}$ Dong Traditional Medicine Hospital. The subjects were interviewed by the a unified medical record, sleep disturbances was diagnosed according to PSQI questionnaire, depression was assessed by GDS-15 and quality of life was assessed by SF-36 questionnaires. Results: Of the 107 paticipants, the rate of poor sleep quality was $89.7 \%$. Patients with poor sleep quality had poorer glycemic control than those in patients with good sleep quality, significantly. Patients with chronic neuropathic pain had a higher rate of poor quality sleep than those in the painless group ( $p<0.05)$. Patients with poor sleep quality had significantly lower quality of physical and mental life than those in patients with good sleep quality ( $\mathrm{p}<0.05)$. There was no statistically significant relationship between depression and poor sleep quality in the population. Conclusion: There is a relationship between sleep quality in elderly diabetic patients and blood glucose control, chronic neuropathic pain and quality of life. Therefore, in clinical practice, early diagnosis and adequate treatment of sleep disorders as well as good blood glucose control help improve the quality of life for elderly diabetic patients.

Key words: Sleep disorder, diabetes, older person, related factors.

\section{TÓM TẮT}

Muc tiêu: Tìm hiểu một số yếu tố liên quan đến rối loạn giấc ngủ trên bệnh nhân ĐTĐ cao tuổi tại bệnh viện y học cổ truyền Hà Đông. Đối tương và phuơng pháp: Nghiên cứu mô tả cắt ngang trên 107 bệnh nhân $\geq 60$ tuổi đến khám và điều trị tại bệnh viện $\mathrm{Y}$ học cổ truyền Hà Đông. Đối tượng nghiên cứu được phỏng vấn theo mẫu bệnh án thống nhất, chẩn đoán chất lượng giấc ngủ kém dựa trên thang điểm PSQI, trầm cảm đánh giá dựa trên thang điểm GDS-15 và chất lượng cuộc sống được đánh giá bằng bộ câu hỏi SF-36. Kết quả: Tỷ lệ chất lượng giấc ngủ kém là 89,7\%. Bệnh nhân có chất lượng giấc ngủ kém có kiểm soát đường máu kém hơn so với nhóm bệnh nhân có chất lượng giấc ngủ tốt $(\mathrm{p}<0,05)$. Bệnh nhân có đau mạn tính do nguyên nhân thần kinh có tỉ lệ chất lượng giấc ngủ kém cao hơn so với nhóm không đau $(\mathrm{p}<0,05)$. Bệnh nhân có chất lượng giấc ngủ kém có chất lượng cuộc sống thể chất, tinh thần kém hơn so với bệnh nhân có chất lượng giấc ngủ tốt $(\mathrm{p}<0,05)$. Không có mối liên quan có ý nghĩa thống kê giữa trầm cảm với tỉ lệ chất lượng giấc ngủ kém ở đối tượng nghiên cứu. Kết luận: Có mối liên quan giữa chất lượng giấc ngủ ở bệnh nhân ĐTĐ cao tuổi với kiểm soát đường máu, đau do biến chứng thần kinh và chất lượng cuộc sống. Vì vậy, trong thực hành lâm sàng cần chẩn đoán sớm và điều trị đầy đủ rối loạn giấc ngủ cũng như kiểm soát đường máu tốt giúp nâng cao chất lượng cuộc sống cho bệnh nhân.

Tù khóa: Rối loạn giấc ngủ, đái tháo đường, cao tuổi, yếu tố liên quan

Chịu trách nhiệm chính: Nguyễn Trung Anh

Ngày nhận bài: 10/10/2020

Ngày phản biện khoa học: 08/11/2020

Ngày duyệt bài: 11/12/2020

Email: trunganhvlk@gmail.com

Điện thoại: 0903480774 


\section{1. ĐẶT VẤN ĐỀ}

Theo Tổ chức Y tế Thế giới, rối loạn giấc ngủ là một vấn đề cực kỳ nghiêm trọng của thế kỷ 21. Một giấc ngủ ngon và chất lượng là một giấc ngủ cần phải đáp ứng: đủ về số lượng và đảm bảo về chất lượng. Bốn triệu chứng chính đặc trưng nhất của các rối loạn giấc ngủ là: chứng mất ngủ, ngủ nhiều, các rối loạn liên quan đến giấc ngủ và rối loạn nhịp thức ngủ... Những triệu chứng này thường gối lên nhau [1]. Tỉ lệ rối loạn giấc ngủ và chất lượng giấc ngủ kém ở người cao tuổi khá cao. Trong dân số Trung Quốc, tỷ lệ chất lượng giấc ngủ kém là $45,8 \%$ ở phụ nữ cao tuổi và cao hơn so với nam giới cao tuổi $(35,8 \%)$. Tỷ lệ này tăng theo tuổi, từ $32,1 \%$ (từ 60-69 tuổi) lên $52,5 \%$ (tuổi $\geq 80$ tuổi) [2]. Một nghiên cứu khác ở Thái Lan ghi nhận tỷ lệ chất lượng giấc ngủ kém ở những người cao tuổi điều trị ngoại trú là $70,8 \%$, tỉ lệ thời gian ngủ ngắn $(99,7 \%)$, hiệu quả giấc ngủ kém $(61,6 \%)$ và rối loạn giấc ngủ ban ngày $(51,6 \%)$ [3].

Nhiều nghiên cứu chỉ ra rằng đái tháo đường (ĐTĐ) làm tăng nguy cơ rối loạn giấc ngủ đặc biệt ở người cao tuổi. Một nghiên cứu lâm sàng đã chỉ ra rằng có tới một phần ba số bệnh nhân mắc ĐTĐ bị rối loạn giấc ngủ so với $8.2 \%$ ở nhóm không mắc ĐTĐ [4]. Trong một nghiên cứu khác, hơn một nửa số bệnh nhân mắc ĐTĐ typ 2 có báo cáo là chất lượng giấc ngủ kém theo một cuộc thăm dò được tiến hành nghiên cứu tại Đại học Pittsburgh. Trong một mẫu nghiên cứu trên cộng đồng lớn gồm 3282 người trưởng thành ghi nhận bệnh nhân ĐTĐ có nguy cơ mất ngủ cao hơn 1,4 lần ở bệnh nhân không mắc ĐTĐ. Những bệnh nhân ngủ kém được phát hiện gặp khó khăn trong việc kiểm soát đường huyết [4]. Đặc biệt, rối loạn giấc ngủ có thể có mối liên quan với các yếu tố như tuổi cao, các bệnh mắc kèm, kiểm soát đường huyết, trầm cảm và chất lượng cuộc sống ở bệnh nhân cao tuổi.

Bệnh viện $Y$ học cổ truyền Hà Đông là bênh viện hạng II trực thuộc Sở y tế Hà Nội đang bước đầu triển khai nhiều kĩ thuật mới và nâng cao chất lượng khám chữa bệnh, đặc biệt quan tâm các bệnh mạn tính như ĐTĐ ở người cao tuổi. Các nghiên cứu về rối loạn giấc ngủ ở bệnh nhân ĐTĐ cao tuổi còn hạn chế. Do đó, chúng tôi tiến hành nghiên cứu đề tài này với mục tiêu tìm hiểu một số yếu tố liên quan đến rối loạn giấc ngủ trên bệnh nhân ĐTĐ cao tuổi tại Bệnh viện Y học cổ truyền Hà Đông.

\section{2. ĐỐI TỰ̛̣G VÀ PHƯƠNG PHÁP NGHIÊN CÚU}

Nghiên cứu được thực hiện trên 107 bệnh nhân ĐTĐ cao tuổi khám và điều trị tại Bệnh viện $\mathrm{Y}$ học cổ truyền Hà Đông từ tháng 05/2019 đến tháng 11/2019.

\section{1. Đối tượng nghiên cứu}

Tiêu chuẩn chọn đối tượng nghiên cứu: Bệnh nhân $\geq 60$ tuổi được chẩn đoán ĐTĐ theo tiêu chuẩn của Tổ chức $\mathrm{Y}$ tế Thế giới năm 2006.

Tiêu chuẩn loại trừ: Bệnh nhân không thể hoàn thành bộ câu hỏi phỏng vấn hoặc bệnh nhân không đồng ý tham gia nghiên cứu.

\subsection{Phương pháp nghiên cứu}

Thiết kế nghiên cứu: mô tả cắt ngang theo phương pháp chọn mẫu toàn bộ lần lượt chọn các bệnh nhân đến khám và điều trị tại khoa Nội, Bệnh viện Y học cổ truyền Hà Đông từ tháng 05/2019 đến tháng 11/2019. Quá trình thăm khám được tiến hành theo mẫu bệnh án thống nhất.

Các biến số nghiên cứu: Chẩn đoán rối loạn giấc ngủ theo chỉ số chất lượng giấc ngủ Pittsburgh (Pittsburgh Sleep Quality Index PSQI) [5]. Đánh giá tổng điểm PSQI: $\geq 8$ điểm là chất lượng giấc ngủ kém, $<8$ điểm là giấc ngủ bình thường. Trầm cảm được đánh giá bằng thang điểm 15 câu hỏi đánh giá trầm cảm ở người cao tuổi (Geriatric Depression Scale 15 item - GDS-15). Chất lượng cuộc sống được đánh giá bằng bộ câu hỏi SF-36. Các thông tin chung về đối tượng: tuổi, giới, trình độ học vấn, nơi sống, bệnh đồng mắc, tiền sử ĐTĐ, thời gian phát hiện bệnh, biến

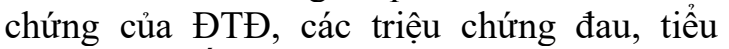
đêm. Các kết quả xét nghiệm máu: đường máu lúc đói, HbA1c.

\subsection{Xử lý số liệu:}

Số liệu được xử lý và phân tích bằng phần mềm thống kể y học SPSS 16.0. Sử dụng các 
thuật toán: tính tỷ lệ phần trăm, tính giá trị trung bình. Sử dụng test $\chi^{2}$ để phân tích mối liên quan giữa các biến. Sự khác biệt có ý nghĩa thống kê khi $\mathrm{p}<0,05$.

\section{KẾT QUẢ NGHIÊN CÚ'U}

\section{1. Đặc điểm chung}

Trong tổng số 107 bệnh nhân nghiên cứu có 96 bệnh nhân có chất lượng giấc ngủ kém chiếm $89,7 \%$. Tỉ lệ chất lượng giấc ngủ kém ở bệnh nhân $\geq 70$ tuổi là $100 \%$, ở nhóm tuổi $60-69$ là 87,4\% Tỉ lệ chất lượng giấc ngủ kém ở nữ là $93 \%$ và ở nam là $83,3 \%$. Thời gian mắc ĐTĐ trung bình là $9,6 \pm 4,9$ (năm). Không có mối liên quan có ý nghĩa thống kê giữa tuổi, giới, thời gian mắc ĐTĐ, hạ đường huyết và số biển chứng của ĐTĐ và tình trạng chất lượng giấc ngủ kém.

\subsection{Các yếu tố liên quan đến rối loạn giấc ngủ ở bệnh nhân ĐTĐ cao tuổi}

- Liên quan giữa chất luợng giấc ngủ và trầm cảm

Bảng 1. Mối liên quan giữa chất lượng giấc ngủ và trầm cảm

\begin{tabular}{|c|c|c|c|}
\hline \multirow{2}{*}{ Trầm cảm } & $\begin{array}{c}\text { Chất lượng giấc ngủ } \\
\text { tốt }(\mathbf{n = 1 1 )}\end{array}$ & $\begin{array}{c}\text { Chất lượng giấc ngủ } \\
\text { kém (n=96) }\end{array}$ & \multirow{2}{*}{$\mathbf{p}$} \\
\hline Không & $10(90,9 \%)$ & $79(82,3 \%)$ & \multirow{2}{*}{0,469} \\
\hline Có & $1(9,1 \%)$ & $17(17,7 \%)$ & \\
\hline
\end{tabular}

Không có mối liên quan có ý nghĩa thống kê giữa trầm cảm và tình trạng chất lượng giấc ngủ kém $(\mathrm{p}>0,05)$.

- Liên quan giữa chất lựng giấc ngủ và đau, đi tiểu đêm

Bảng 2. Mối liên quan giữa chất lượng giấc ngủ và đau, đi tiểu đêm

\begin{tabular}{|c|c|c|c|}
\hline Đặc điểm & $\begin{array}{c}\text { Chất lượng giấc ngủ } \\
\text { tốt }(n=11)\end{array}$ & $\begin{array}{l}\text { Chất lượng giấc ngủ } \\
\text { kém }(n=96)\end{array}$ & $\mathbf{p}$ \\
\hline \multicolumn{4}{|l|}{ Đau mạ tính } \\
\hline Không & $3(17,7 \%)$ & $14(82,3 \%)$ & \multirow{2}{*}{0,376} \\
\hline Có & $8(8,9 \%)$ & $82(91,1 \%)$ & \\
\hline \multicolumn{4}{|l|}{ Đau cấp tính } \\
\hline Không & $8(9,0 \%)$ & $81(91,0 \%)$ & \multirow{2}{*}{0,393} \\
\hline Có & $3(16,7 \%)$ & $15(83,3 \%)$ & \\
\hline \multicolumn{4}{|c|}{ Đau liên quan đến biến chứng thần kinh } \\
\hline Không & $9(17,3 \%)$ & $43(82,7 \%)$ & \multirow{2}{*}{$\mathbf{0 , 0 2 5}$} \\
\hline Có & $2(3,6 \%)$ & $53(96,4 \%)$ & \\
\hline \multicolumn{4}{|l|}{ Tiểu đêm } \\
\hline Không & $1(50,0 \%)$ & $1(50,0 \%)$ & \multirow{2}{*}{0,196} \\
\hline Có & $10(9,5 \%)$ & $95(90,5 \%)$ & \\
\hline
\end{tabular}

Triệu chứng đau liên quan đến biến chứng thần kinh có mối liên quan có ý nghĩa thống kê với tình trạng chất lượng giấc ngủ kém $(\mathrm{p}<0,05)$.

- Liên quan giữa chất lự̛ng giấc ngủ và kiểm soát đường huyết

Bảng 3. Mối liên quan giữa chất lượng giấc ngủ và chỉ số đường máu đói, $\mathrm{HbA} 1 \mathrm{C}$

\begin{tabular}{|c|c|c|c|}
\hline \multicolumn{1}{|c|}{ Đặc điểm } & $\begin{array}{c}\text { Chất lượng giấc ngủ tốt } \\
(\mathbf{n = 1 1})\end{array}$ & $\begin{array}{c}\text { Chất lượng giấc ngủ kém } \\
(\mathbf{n = 9 6 )}\end{array}$ & $\mathbf{p}$ \\
\hline $\begin{array}{l}\text { Đường máu lúc } \\
\text { đói }(\mathrm{mmol} / \mathrm{l})\end{array}$ & $6,57 \pm 0,79$ & $7,96 \pm 2,25$ & $\mathbf{0 , 0 4 6}$ \\
\hline$\leq 7,2$ & $8(16,7)$ & $40(83,3)$ & 0,063 \\
\hline
\end{tabular}




\begin{tabular}{|c|c|c|c|}
\hline$>7,2$ & $3(5,2)$ & $55(94,8)$ & \\
\hline Chỉ số HbA1c (\%) & $5,94 \pm 0,54$ & $6,78 \pm 1,15$ & $\mathbf{0 , 0 1 9}$ \\
\hline$<7,0$ & $11(16,4)$ & $56(83,6)$ & \multirow{2}{*}{$\mathbf{0 , 0 0 6}$} \\
\hline$\geq 7,0$ & $0(0,0)$ & $40(100,0)$ & \\
\hline
\end{tabular}

Bệnh nhân có chất lượng giấc ngủ kém có kiểm soát đường máu kém hơn so với nhóm bệnh nhân có chất lượng giấc ngủ tốt $(\mathrm{p}<0,05)$. Giá trị đường máu lúc đói và $\mathrm{HbA} 1 \mathrm{c}$ trung bình ở nhóm có chất lượng giấc ngủ kém cao hơn so với nhóm có chất lượng giấc ngủ tốt có ý nghĩa thống kê $(\mathrm{p}<0,05)$.

\section{- Liên quan giữa chất lựng giấc ngủ và chất lựng cuộc sống}

Bảng 4. Mối liên quan giữa chất lượng giấc ngủ và chất lượng cuộc sống

\begin{tabular}{|c|c|c|c|}
\hline Đặc điểm & $\begin{array}{c}\text { Chất lượng giấc ngủ tốt } \\
(\mathbf{n = 1 1})\end{array}$ & $\begin{array}{c}\text { Chất lượng giấc ngủ kém } \\
(\mathbf{n = 9 6 )}\end{array}$ & $\mathbf{p}$ \\
\hline Sức khỏe thể chất & $53,43 \pm 9,23$ & $36,05 \pm 9,63$ & $<\mathbf{0 , 0 0 1}$ \\
\hline Sức khỏe tinh thần & $60,93 \pm 8,69$ & $48,09 \pm 7,64$ & $<\mathbf{0 , 0 0 1}$ \\
\hline Tổng điểm SF-36 & $97,10 \pm 2,72$ & $93,85 \pm 3,21$ & $\mathbf{0 , 0 0 3}$ \\
\hline
\end{tabular}

Bệnh nhân có chất lượng giấc ngủ kém có các đặc điểm của chất lượng cuộc sống cả thể chất và tinh thần kém hơn so với nhóm bệnh nhân có chất lượng giấc ngủ tốt $(\mathrm{p}<0,05)$.

\section{BÀN LUẬN}

Nghiên cứu của chúng tôi ghi nhận tỉ lệ bệnh nhân có chất lượng giấc ngủ kém là $89,7 \%$ với 7 phương diện đánh giá rối loạn giấc ngủ (rối loạn giấc ngủ chủ quan, độ trễ giấc ngủ, thời gian ngủ, rối loạn giấc ngủ, dùng thuốc ngủ, hiệu quả giấc ngủ, rối loạn chức năng ban ngày), đa số các bệnh nhân có mức độ chất lượng/rối loạn giấc ngủ ở mức tương đối kém. Tỷ lệ này cao hơn so với kết quả nghiên cứu của ở Thái Lan ghi nhận tỷ lệ chất lượng giấc ngủ kém ở những người cao tuổi điều trị ngoại trú là $70,8 \%$, tỉ lệ thời gian ngủ ngắn $(99,7 \%)$, hiệu quả giấc ngủ kém $(61,6 \%)$ và rối loạn giấc ngủ ban ngày $(51,6 \%)$ [3]. Kết quả này có thể là do đối tượng nghiên cứu của chúng tôi là bệnh nhân ĐTĐ cao tuổi nên chất lượng giấc ngủ bị ảnh hưởng bởi nhiều yếu tố như tuổi cao, nhiều bệnh lý mắc kèm và các hội chứng lão khoa.

Kết quả nghiên cứu của chúng tôi cũng chỉ ra có mối liên quan có ý nghĩa thống kê giữa triệu chứng đau liên quan đến biến chứng thần kinh và tỉ lệ chất lượng giấc ngủ kém ở đối tượng bệnh nhân ĐTĐ typ 2 cao tuổi điều trị tại bệnh viện Y học cổ truyền Hà Đông. Bệnh nhân có triệu chứng đau liên quan đến biến chứng thần kinh của ĐTĐ có tỉ lệ chất lượng giấc ngủ kém cao hơn so với bệnh nhân không có triệu chứng đau liên quan đến biến chứng thần kinh ngoại vi của ĐTĐ. Tuy nhiên, không có mối liên quan có ý nghĩa thống kê giữa trầm cảm, triệu chứng đau cấp và mạn tính, tình trạng tiểu đêm và tỉ lệ chất lượng giấc ngủ kém ở đối tượng nghiên cứu. Kết quả này có thể do cỡ mẫu của chúng tôi còn nhỏ và là nghiên cứu cắt ngang.

Nghiên cứu của chúng tôi ghi nhận có mối liên quan có ý nghĩa thống kê giữa chỉ số đường máu đói và $\mathrm{HbA} 1 \mathrm{c}$ trung bình và tỉ lệ chất lượng giấc ngủ kém ở đối tượng bệnh nhân ĐTĐ cao tuổi. Bệnh nhân có chất lượng giấc ngủ kém có chỉ số đường máu đói trung bình $(7,96 \pm 2,25 \mathrm{mmol} / \mathrm{l})$ cao hơn có ý nghĩa thống kê so với bệnh nhân có chất lượng giấc ngủ tốt $(6,57 \pm 0,79 \mathrm{mmol} / \mathrm{l})$. Bệnh nhân có chất lượng giấc ngủ kém có chỉ số $\mathrm{HbA1c}$ trung bình $(6,78 \pm 1,15 \%)$ cao hơn có ý nghĩa thống kê so với bệnh nhân có chất lượng giấc ngủ tốt $(5,94 \pm 0,54 \%)$. Bệnh nhân nghiên cứu được chia ra 2 nhóm: nhóm kiểm soát đường máu tốt $(\mathrm{HbA} 1 \mathrm{c}<7 \%)$ và nhóm kiểm soát đường máu kém $(\mathrm{HbAlc} \geq 7 \%)$. Nhóm kiểm soát đường máu kém có tỉ lệ chất lượng giấc 
ngủ kém là $100 \%$ (40 bệnh nhân) cao hơn có ý nghĩa thống kê với nhóm kiểm soát đường máu tốt thì tỉ lệ này là $83,6 \%$ (56 bệnh nhân) với $\mathrm{p}<0,05$. Kết quả này tương tự nghiên cứu của Bing-Qian Zhu (2014) trên 220 bệnh nhân ĐTĐ typ 2 cũng ghi nhận $\mathrm{HbA1c} \geq 7 \%$ có liên quan với tỷ lệ chất lượng giấc ngủ kém và chỉ số PSQI trung bình cao hơn có ý nghĩa thống kê [6].

Chất lượng cuộc sống của bệnh nhân ĐTĐ cao tuổi bị ảnh hưởng nhiều bởi rối loạn giấc ngủ. Kết quả của nghiên cứu ghi nhận bệnh nhân có chất lượng giấc ngủ kém có chất lượng cuộc sống (đánh giá bằng thang điểm SF-36) kém hơn bệnh nhân có chất lượng giấc ngủ tốt có ý nghĩa thống kê $(\mathrm{p}<0,05)$ ở nhiểu lĩnh vực: sức khỏe thể chất và sức khỏe tinh thần. Kết quả này cũng tương tự kết quả nghiên cứu của Luyster và cộng sự (2011) ghi nhận ảnh hưởng của chất lượng giấc ngủ lên chất lượng cuộc sống của bệnh nhân ĐTĐ typ 2 [7].

\section{KẾT LUẬN}

Tóm lại, có mối liên quan giữa chất lượng giấc ngủ ở bệnh nhân ĐTĐ cao tuổi với kiểm soát đường máu, đau do biến chứng thần kinh và chất lượng cuộc sống. Vì vậy, trong thực hành lâm sàng cần chẩn đoán sớm và điều trị đầy đủ rối loạn giấc ngủ cũng như kiểm soát đường máu tốt giúp nâng cao chất lượng cuộc sống cho bệnh nhân.

\section{TÀI LIỆU THAM KHẢO}

1. K. Suzuki, M. Miyamoto, K.
Hirata(2017). Sleep disorders in the elderly: Diagnosis and management. $J$ Gen Fam Med, 18(2), 61-71

2. J. Luo, et al. (2013) Prevalence and risk factors of poor sleep quality among Chinese elderly in an urban community: results from the Shanghai aging study. PloS one, 2013. 8(11): p. e81261

3. W. Aunjitsakul, et al. (2017) Sleep quality among elderly people within the outpatient department of Songklanagarind Hospital, Thailand: a cross-sectional study. Songklanagarind Medical Journal, 2017. 35(3): p. 195-204.

4. S. Surani, V. Brito, A. Surani et al. (2015). Effect of diabetes mellitus on sleep quality. World J Diabetes, 6(6), 868873.

5. D. J. R. Buysse, Charles F.; Monk, Timothy H.; Berman, Susan R.; Kupfer, David J. (1989). "The Pittsburgh sleep quality index: A new instrument for psychiatric practice and research". Psychiatry Research. 28 (2): 193-213.

6. X.-M. Bing-QianZhu, DanWang, XingFengYu (2014). Sleep quality and its impact on glycaemic control in patients with type 2 diabetes mellitus. International Journal of Nursing Sciences, 1(3), 260-265.

7. F. S. Luyster, J. Dunbar-Jacob (2011). Sleep quality and quality of life in adults with type 2 diabetes. Diabetes Educ, 37(3), 347-355. 